\title{
EXTERNAL AND INTERNAL WAVE SET-UP AT POROUS PBA REVETMENTS ON A SAND FOUNDATION
}

\author{
Gisa Foyer ${ }^{1}$ and Hocine Oumeraci ${ }^{1}$
}

\begin{abstract}
Wave set-up is generally considered for the stability analysis of beaches, but not or not explicitly for the design of revetments. Based on large-scale model results with regular and irregular waves, it is shown in this paper that this is not justified. For this purpose, the wave set-up on a porous bonded revetment and the related internal set-up in the sand foundation below the revetment are analysed for different breaker types. The results particularly show that (i) considerable set-up values are obtained for almost all breaker types, (ii) a good correlation exists with the deep water wave length for both external and internal set-up and (iii) the internal set-up is significantly affected by the wave set-up on the slope. Empirical formulae for the prediction of the external and internal set-up are also proposed for both regular and irregular waves.
\end{abstract}

Keywords: porous bonded revetment, wave set-up, wave set-down, internal set-up, breaker types

\section{INTRODUCTION}

Polyurethane bonded aggregate (PBA) revetments enable the construction of highly porous structures to dissipate wave energy and to reduce wave run-up. Therefore, such revetments may constitute a proper alternative to strengthen dikes and embankments without heightening them. However, the effects associated with the high porosity of PBA revetments are still poorly understood. For this purpose, a systematic study in large-scale was performed in the Large Wave Flume (GWK) in Hannover, Germany. The results on the hydraulic performance, the wave loading and the response of the soil foundation have already been reported in many reports and papers. While most of the results are described in a detailed internal report (Oumeraci et al. 2010b) and are summarised in Oumeraci et al. 2012; part of the findings are published in Oumeraci et al. (2010a) (reflection performance, wave run-up and run-down and failure of model alternative A) and Ludwigs et al. (2010) (loads on and beneath the revetment) as well as Ludwigs \& Oumeraci (2011) (load-displacement - pore pressure relations).

This paper aims at analysing the wave set-up at different porous revetments as well as the effect on the water table in the sand core. First, the experimental set-up and the testing programme are described. Second, the wave set-up on the revetment and the wave set-down in front of the shoreline are analysed for all revetment model alternatives tested with regular and irregular waves. Based on these results, the related internal set-up in the sand foundation is investigated for different breaker types. Finally, empirical formulae for the prediction of the wave set-up on the slope and the related internal set-up in the sand foundation beneath the revetment are proposed for regular and irregular waves and a short outlook on further investigations is given.

\section{EXPERIMENTAL SET-UP AND TESTING PROGRAMME}

Systematic large-scale model tests on three model alternatives of porous, polyurethane bonded aggregate (PBA) revetments were performed in 2009 in the Large Wave Flume (GWK) in Hannover, Germany (Figure 1). The flume has a length of over $300 \mathrm{~m}$, is $5 \mathrm{~m}$ wide and $7 \mathrm{~m}$ deep. All model alternatives had a slope steepness of 1:3 but different revetment alternatives were used as shown in Figure 1b. Two alternatives were installed side by side in the flume and tested simultaneously under the same wave conditions starting with model alternatives A and B. After the failure of model alternative $\mathrm{A}$, it was removed and replaced with alternative $\mathrm{C}$.

\footnotetext{
${ }^{1}$ Leichtweiss-Institute for Hydraulic Engineering and Water Resources, Technische Universitaet Braunschweig, Beethovenstr. 51a, D-38106 Braunschweig, Germany
} 


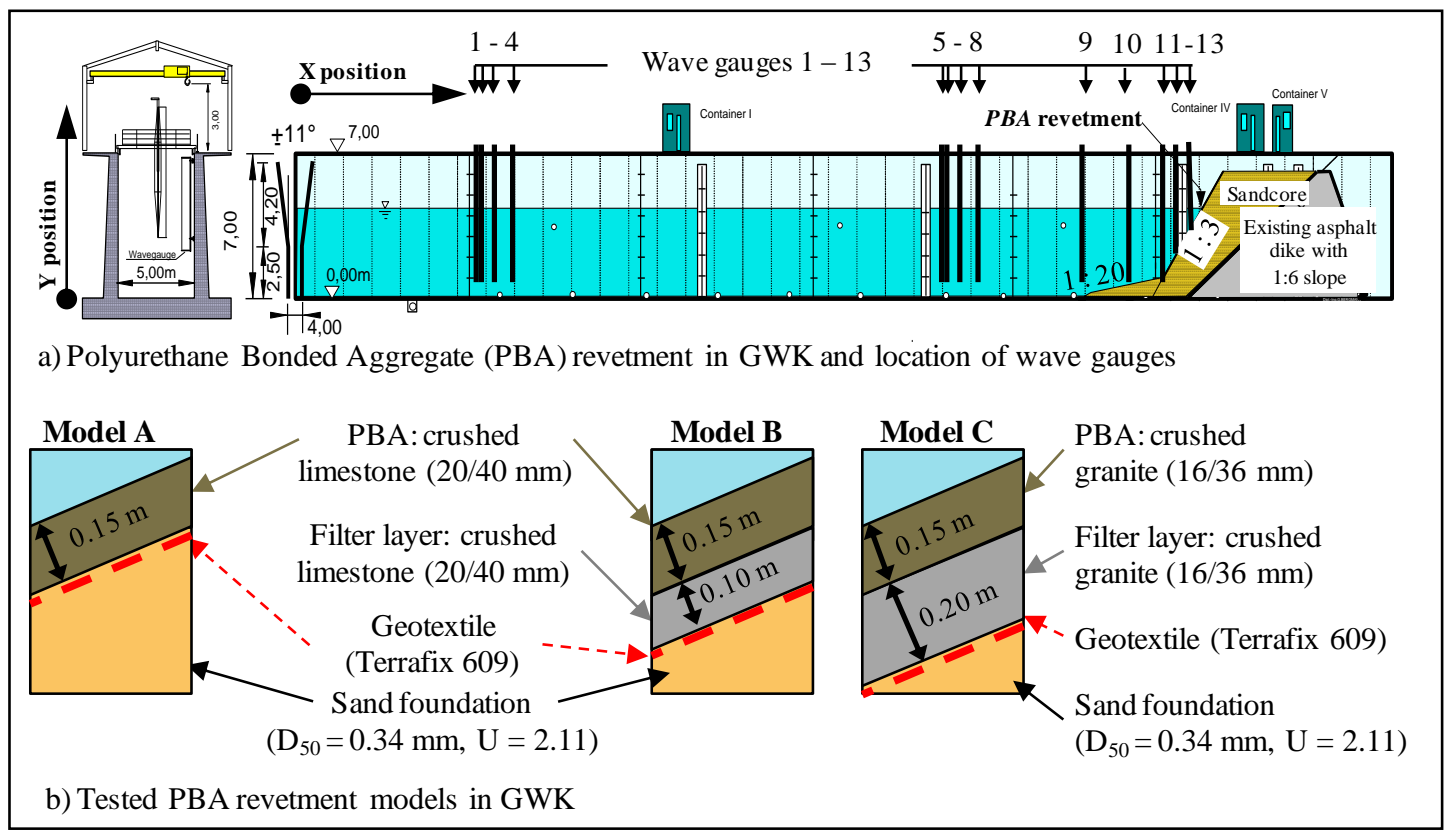

Figure 1. Experimental set-up of the revetment model alternatives in the GWK.

\section{Measuring and observation instruments}

A total of over 80 measuring devices were deployed in the GWK during the experiments including wave gauges, pressure transducers, layer thickness gauges, etc. A complete description of the deployed measuring and observation devices is given in Oumeraci et al. (2010b). For the analysis in this paper, only the measurements by means of the following devices are considered: (i) wave gauges (WG) as shown in Figure 1a; (ii) wave run-up gauges (RUG) on the revetment as shown in Figure 2 and (iii) pore pressure transducers (PT) in the sand core as shown in Figure 2.

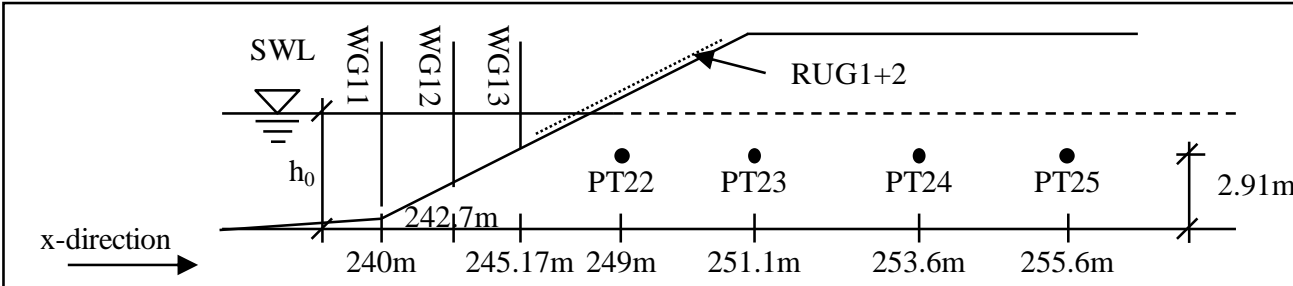

a) Location of wave run-up gauge and pressure transducers in the sand foundation

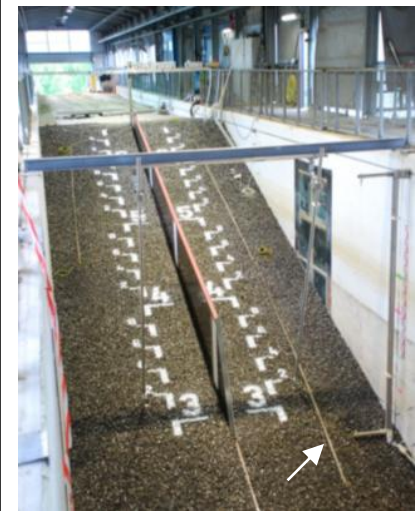

b) Wave run-up gauge (RUG)

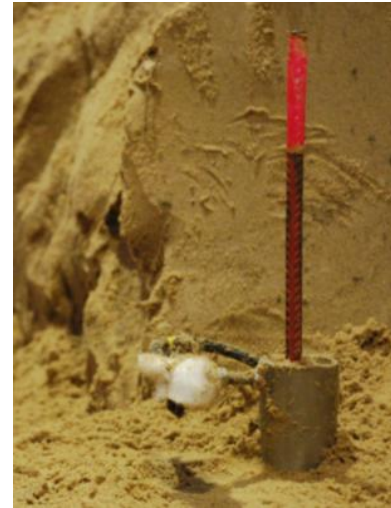

c) Pressure transducer (PT)

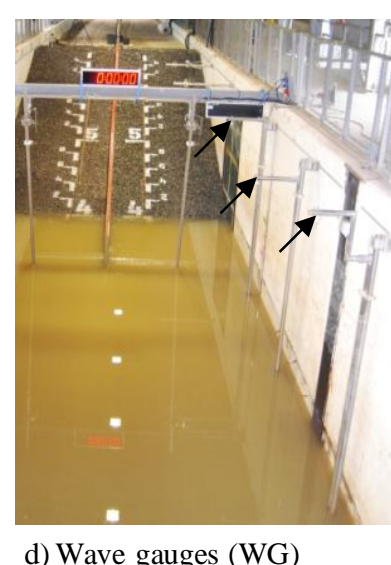

d) Wave gauges (WG)

Figure 2. Measuring devices in the GWK considered for the analysis in this study. 
The wave run-up gauges were installed on both model alternatives and consisted of each two resistance wires (Figure 2b). The pressure transducers are fixed in the sand foundation at the locations shown in Figure $2 \mathrm{a}$ and these transducers are protected by a geotextile cover (Figure 2c). The transducers are only placed in the middle of the flume and, therefore, measure the resulting water table behind both revetment alternatives at that time. The wave gauges along the flume are used to perform a reflection analysis and, thus, to determined the incident wave conditions (Figure 1a). The wave gauges directly on the slope (WG10 - 13 in Figure 1a and Figure 2a) are important to calculate the wave setdown in front of the shoreline.

\section{Test programme and testing procedure}

Regular waves and irregular waves (JONSWAP-spectrum) were used in the tests. The wave heights and periods were altered for each test to obtain a wide range of surf similarity parameters. Moreover, the initial water depth in the flume was altered. This procedure resulted in the following range of parameters:

For regular waves: deep water mean wave height $\mathrm{H}_{\mathrm{m}}=0.17-1.4 \mathrm{~m}$ and mean wave period $\mathrm{T}_{\mathrm{m}}=3.0-8.1 \mathrm{~s}$ providing a surf similarity parameter $\xi_{\mathrm{m}}=1.3-8.1$ (see eq. 1 ).

For irregular wave tests: deep water wave height $\mathrm{H}_{\mathrm{m} 0}=0.19-1.17 \mathrm{~m}$ and characteristic wave period $\mathrm{T}_{\mathrm{m}-1,0}=2.7-7.1 \mathrm{~s}$ resulting in a surf similarity parameter $\xi_{\mathrm{m}-1,0}=1.6-6.6$ (see eq. 2 ). For both, regular and irregular wave test, initial water depths of $\mathrm{h}_{0}=3.4-4.2 \mathrm{~m}$ were used.

$$
\begin{gathered}
\xi_{m}=\frac{\tan \alpha}{\sqrt{\frac{H_{m}}{L_{0}}}} \\
\xi_{m-1,0}=\frac{\tan \alpha}{\sqrt{\frac{H_{m 0}}{L_{0}}}}
\end{gathered}
$$

\section{WAVE SET-UP ON THE REVETMENT}

Wave set-up is induced by wave breaking and can be described by the concept of radiation stress as proposed by Longuet-Higgins \& Stewart (1964). According to this concept, during the shoaling processes of the waves the increase of the wave height is balanced by a decrease of the water level (wave set-down) in the breaker zone while the energy dissipation during the breaking process of the wave results in a wave set-up at the revetment slope. Therefore, it is often assumed that a considerable wave set-up only occurs for spilling and plunging breakers which has often led to a focus of the experiments on small surf similarity parameters and thus on beaches with relatively mild slopes. In the following, it is however shown that most of the breaker types result in significant wave set-up.

Moreover, the wave set-up is often described in a non-dimensional form by the wave height $\eta_{S} / H$ and given as a function of the surf similarity parameter $\xi$ (eq. 3).

$$
\frac{\eta_{S}}{H}=f(\xi)
$$

Often, a linear relation is used between $\eta_{S} / H$ and $\xi$ (Hanslow \& Nielsen. 1993; Stockdon et al. 2006). As will be shown later, a different relation is found in this study.

The wave run-up gauges on the slope surface enable a relatively accurate determination of the wave set-up directly on the slope. A mean value of the water level over the test duration can be calculated which is then defined as the wave set-up directly on the slope. An example of the applied procedure is given in Figure $3 \mathrm{a}$ for regular waves. The same procedure is applied for the irregular wave tests, but in this case only a mean wave set-up can be calculated for the complete test duration (see Figure 3b).

Similar to the determination of the wave set-up, the wave set-down in front of the structure was determined at wave gauges WG10-13 (cf. Figure 1a). A mean water level (MWL) is exemplary shown together with the still water level (SWL) in Figure 4 including the very small wave set-down at the wave gauges on the slope. The lowest point of the MWL is found at WG13 $\left(\eta_{\mathrm{s}, \mathrm{WG} 13}=-0.04 \mathrm{~m}\right)$. Wave breaking is observed at the same location. The wave set-up in this example is quite high with $\eta_{\mathrm{S}, \mathrm{RUG}}=0.54 \mathrm{~m}$ which is about half of the incident mean wave height $\mathrm{H}_{\mathrm{m}}=0.918 \mathrm{~m}$. In the following, the wave gauge with the maximum deviation from the still water level (SWL) is selected for the analysis of the wave set-down. For the example in Figure 4, it is WG13. 


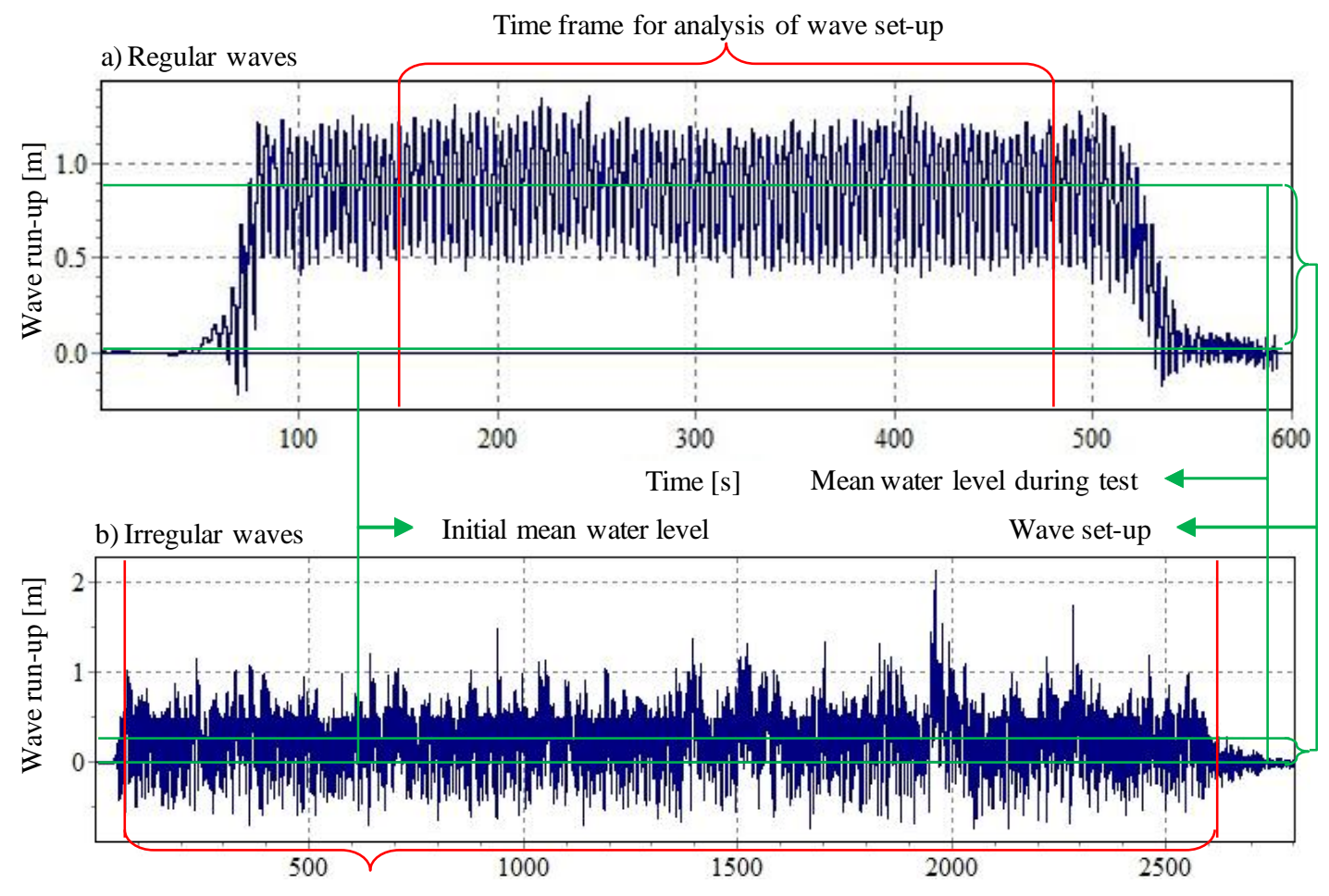

Time frame for analysis of wave set-up Time $[\mathrm{s}]$

Figure 3. Example of the determination of wave set-up on the slope surface for regular and irregular waves.
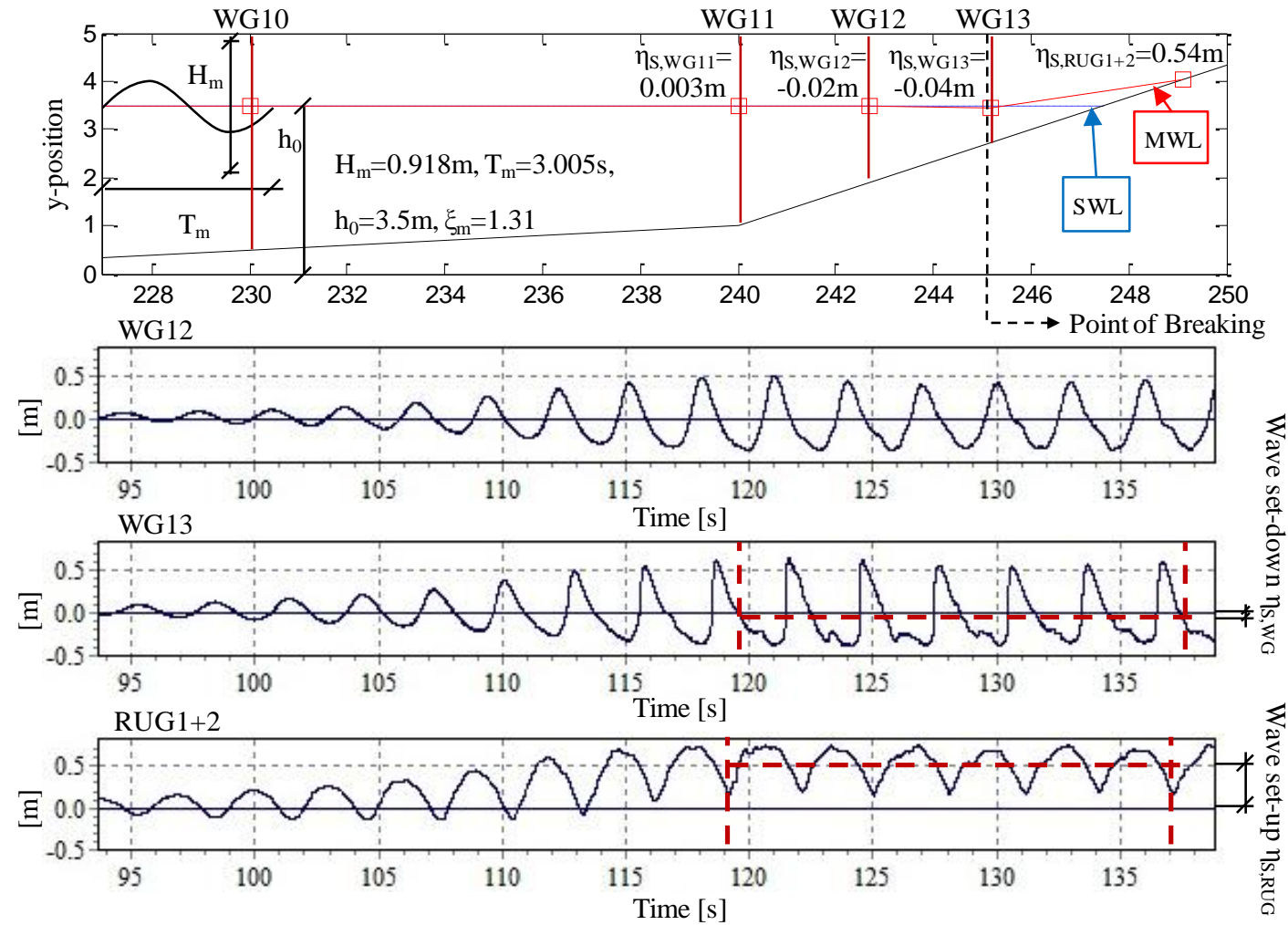

Figure 4. Example of a mean water level (MWL) in front of the revetment for regular waves. 


\section{Regular wave tests}

Based on the above described procedure, the wave set-up was determined for all tests with regular waves. As shown in Figure 5, the commonly used relation between relative wave set-up and surf similarity parameter $\xi$ (see eq. 3 ) is applied to all model alternatives. In the analysis, the relative wave set-up is defined as $\eta_{\mathrm{S}, \mathrm{RUG}} / \mathrm{H}_{\mathrm{m}}$ and the surf similarity parameter $\xi_{\mathrm{m}}$ according to eq. (1). Moreover, the prediction formula (eq. 4) as proposed by Stockdon et al. (2006) is also given in Figure 5 for comparison with the data set generated in this study:

$$
\frac{\eta_{S}}{H}=0.35 \cdot \xi
$$

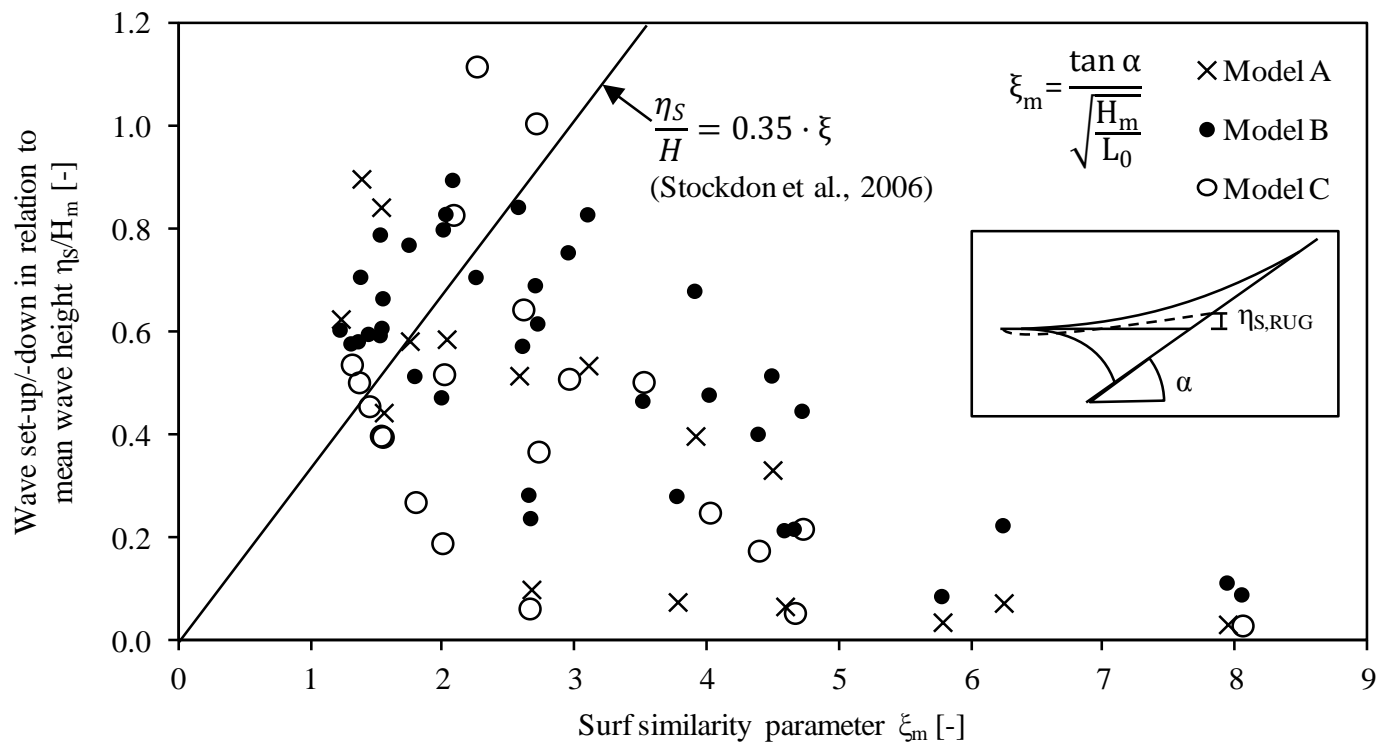

Figure 5. Wave set-up in relation to wave height for regular waves on the slope surface.

No clear correlation between the relative wave set-up and the surf similarity parameter can be observed in Figure 5. Furthermore, the depicted equation by Stockdon et al. (2006), which is a linear function, does not represent the data set, especially for surf similarity parameter $\xi_{\mathrm{m}}>3$. The results in Figure 5 exemplarily illustrate the necessity of a new approach to the analysis of the data set and of better prediction formulae.

For this purpose, the deep water wave length $\mathrm{L}_{0}$ is applied instead of the wave height $\mathrm{H}_{\mathrm{m}}$ to make the wave set-up and wave set-down non-dimensional. The relative wave set-up $\eta_{\mathrm{S}, \mathrm{RUG}} / \mathrm{L}_{0}$ and the relative wave set-down $\eta_{\mathrm{S}, \mathrm{WG}} / \mathrm{L}_{0}$ are plotted in Figure 6 as a function of the surf similarity parameter $\xi_{\mathrm{m}}$. This new approach shows a substantially better correlation than that in Figure 5. As expected, very high relative wave set-up values are obtained for very small values of the surf similarity parameter with a rapid decrease of the relative wave set-up for increasing surf similarity parameter.

No differences are found for the three model alternatives A, B and C in Figure 6. This is somehow expected, because the wave set-up is mainly caused by the energy dissipation during the breaking process, which is not or only slightly affected by the different revetment alternatives. Minor differences between the model alternatives can also be observed in Figure 5.

In addition, Figure 6 shows the relative wave set-down in front of the structure. The absolute relative wave set-down is about an order of magnitude smaller than the wave set-up. In general, a larger wave set-down (absolute value) is found for smaller surf similarity parameter as it was also found for the wave set-up. However, the scatter in the wave set-down data is considerably larger than that of the wave set-up data. 


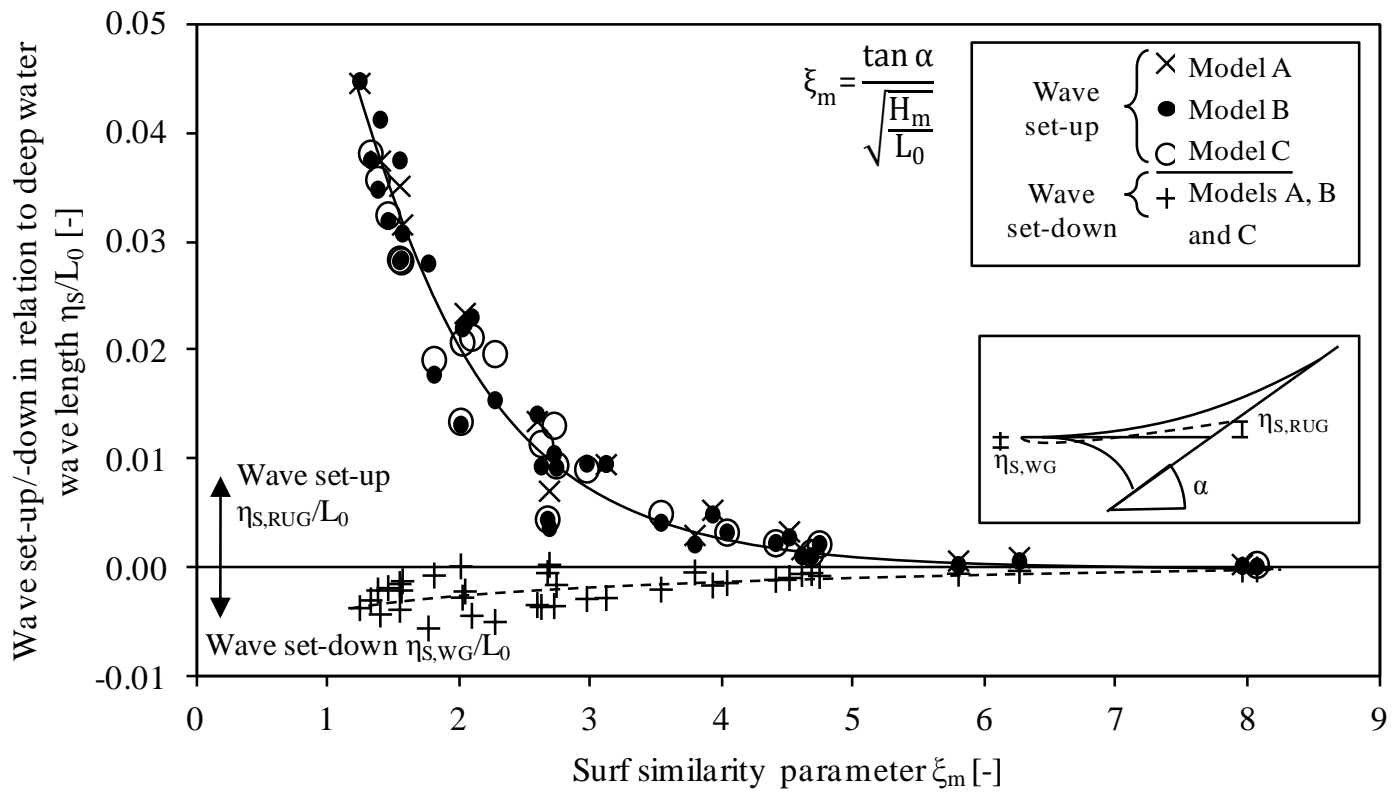

Figure 6. Wave set-up and set-down for regular waves on the slope surface.

\section{Irregular wave tests}

The analysis of the wave set-up was also performed for the tests with irregular waves. The results are shown in Figure 7 together with those of regular wave tests for comparison. The performance of the new approach for the analysis of both, regular and irregular, wave tests is quite similar except for the smaller absolute values for the relative wave set-up and set-down. These smaller values are mostly caused by the nature of the two different test series: for the regular waves, a constant wave set-up and set-down over the test duration is obtained while for irregular waves both values only represent mean values of themselves over the entire test duration (see also Figure 3).

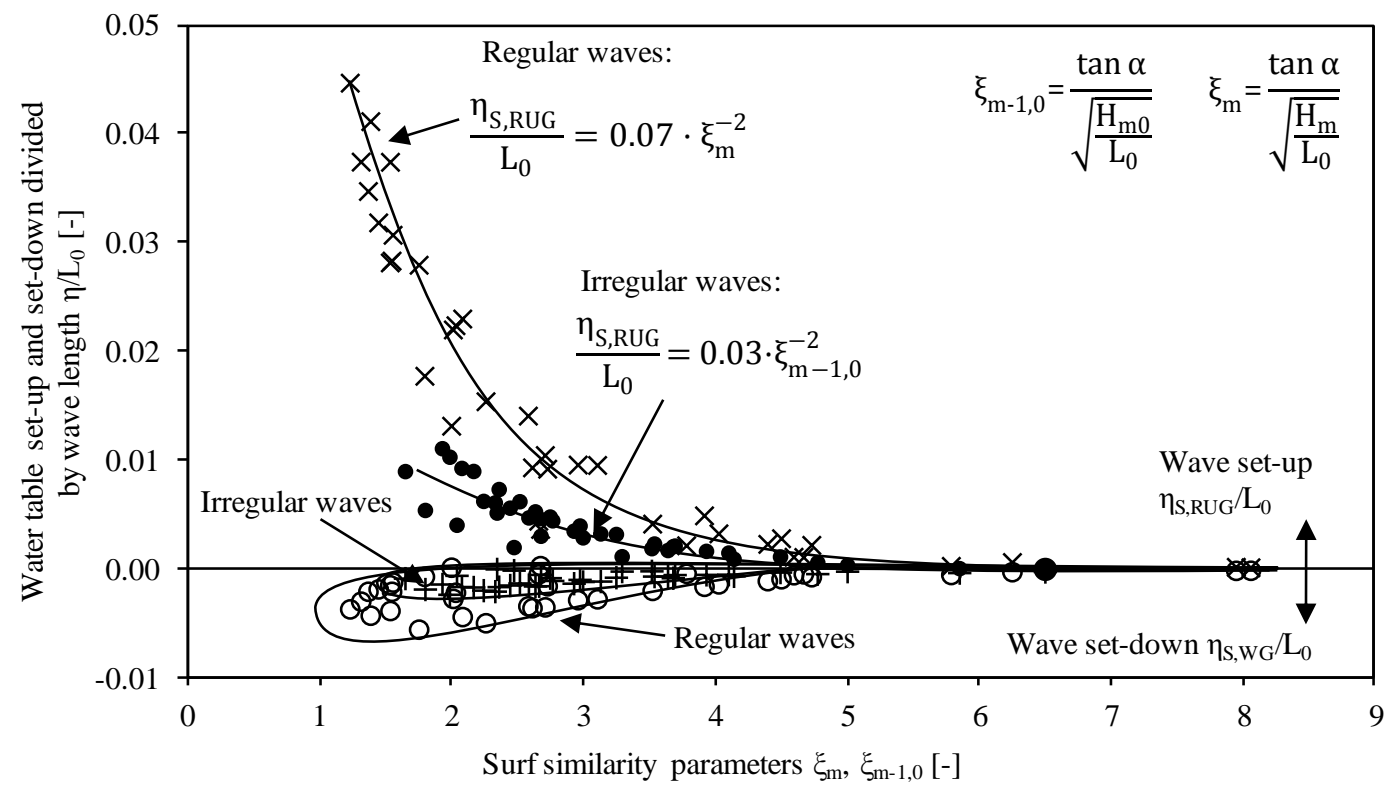

Figure 7. Wave set-up and set-down for regular and irregular waves on the slope.

Based on the results in Figure 7, the following prediction formulae are tentatively proposed for regular and irregular waves (see eqs. $1 \& 2$ for the definition of the surf similarity parameter $\xi$ ): 


$$
\begin{gathered}
\text { regular waves: } \frac{\eta_{S, R U G}}{L_{0}}=0.07 \cdot \xi_{m}^{-2} \\
\text { irregular waves: } \frac{\eta_{S, R U G}}{L_{0}}=0.03 \cdot \xi_{m-1,0}^{-2}
\end{gathered}
$$

Contrary to the wave set-up, the wave set-down exhibits a large scatter, so that a prediction equation cannot be developed based on these data. This is most likely caused by the larger spatial distribution of the wave gauges compared to the much higher spatial resolution provided by the wave run-up gauges. Further investigations are, therefore, needed to obtain higher resolution data for the wave set-down.

\section{INTERNAL WAVE SET-UP BENEATH THE REVETMENT}

The very few published studies available on the internal wave set-up generally focus on long waves. Barends \& van Hoven (2007) developed an analytical solution for the internal set-up and determined the maximum internal set-up for a closed-end dike at the closed end of the structure. The same is predicted by Losada et al. (1998) who investigated the set-up in a vertical porous medium but focused on a shallow water solution.

\section{Regular wave tests}

In the present study, the internal set-up was determined at the four pressure transducers (PT) 22 25 as exemplarily shown in Figure 8 for PT22. For the regular wave tests, only the set-up at the end of the recorded time frame is used, because the set-up is still developing during the test (see Figure 8b).

a) Wave run-up and set-up at RUG1+2(model $A) \quad H_{m}=1.403 \mathrm{~m}, \mathrm{~T}_{\mathrm{m}}=3.922 \mathrm{~s}, \mathrm{~h}_{0}=3.7 \mathrm{~m}, \xi_{\mathrm{m}}=1.38$
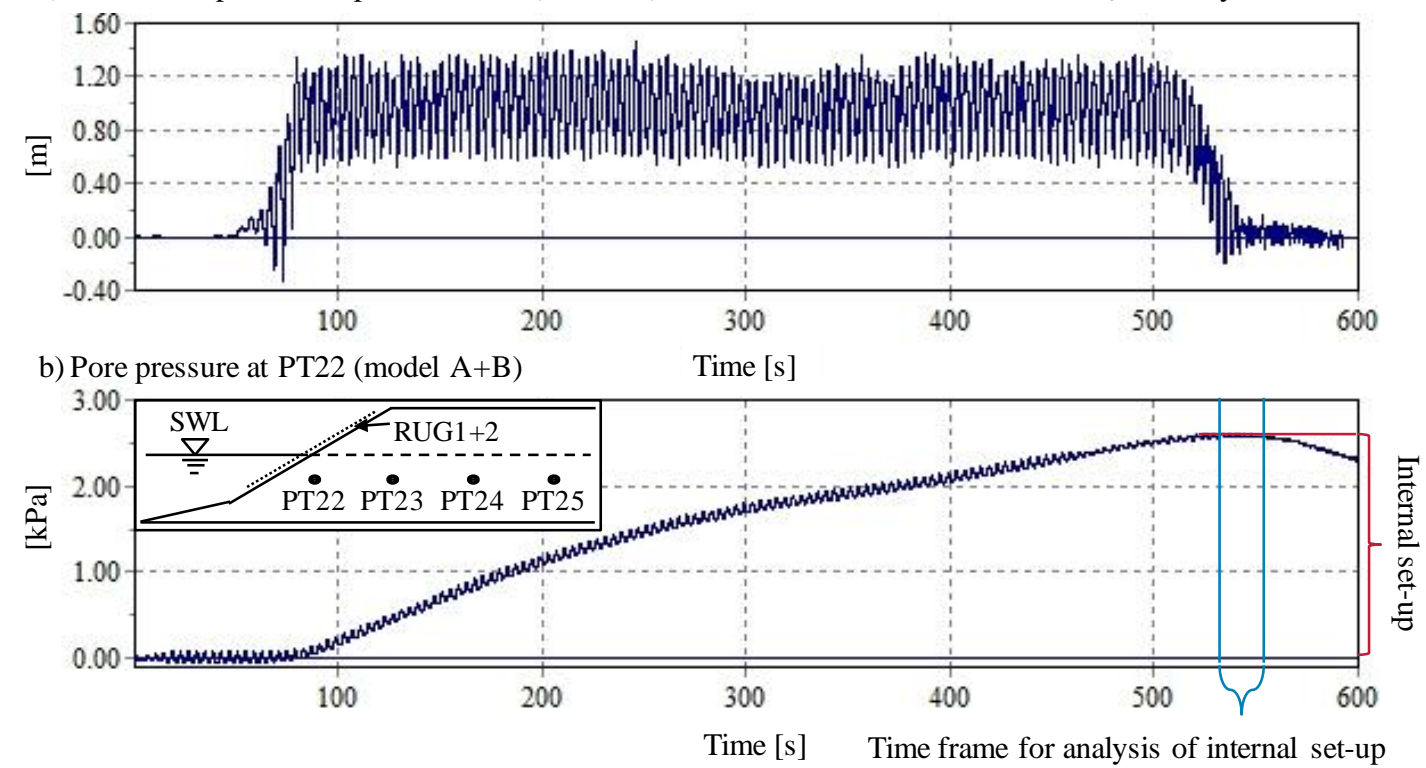

Figure 8. Determination procedure for the internal set-up in the sand foundation for regular waves.

First, four representative tests are selected for the preliminary analysis: one test for each of the four breaker types "plunging", "plunging-collapsing", "collapsing" and "surging" (Figure 9). The resulting external mean water level (EMWL) and internal mean water level (IMWL) are shown with respect to the still water level (SWL). For the breaker types plunging, plunging-collapsing and collapsing, a distinct wave set-down is observed in front of the shoreline. The relation between the maximum internal and external wave set-up significantly differs for the four breaker types: for the plunging breaker the maximum IMWL is about 30\% of the maximum EMWL; for the plunging-collapsing breaker it is about $50 \%$ and for the collapsing breaker it is almost $100 \%$. The results of the surging breaker are too small to be compared to the other values. 


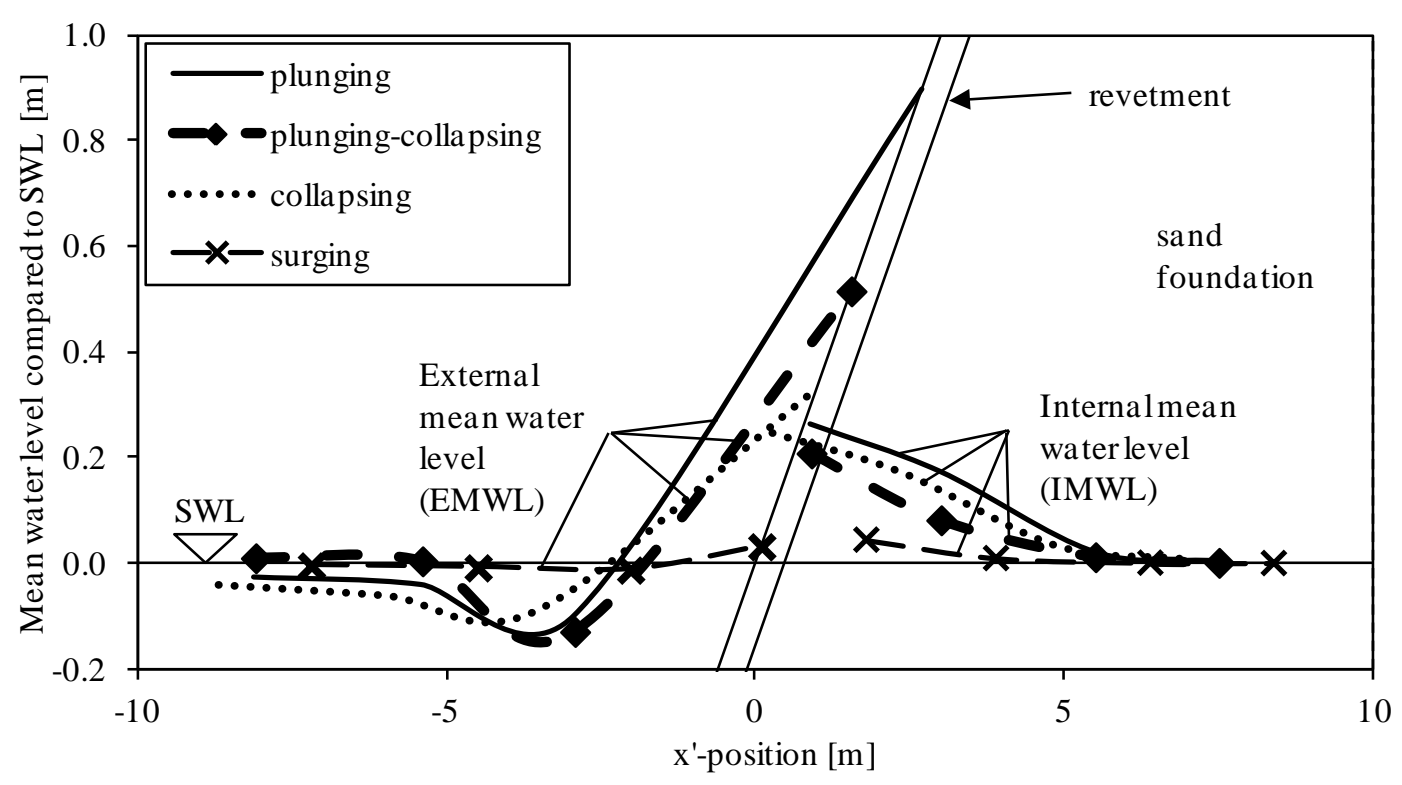

Figure 9. External and internal mean water level for representative tests with regular waves and different breaker types.

Several general observations can be made for the results in Figure 9:

1. The maximum internal wave set-up is similar for the plunging, plunging-collapsing and collapsing breakers even though the associated external wave set-up values significantly differ.

2. Internal mean water level (IMWL) and external mean water level (EMWL) meet at the revetment only for the collapsing breaker case.

3. The maximum internal wave set-up is located at respectively near the revetment surface

Especially the third point is rather unexpected, considering the results from Barends \& van Hoven (2007) and Losada et al. (1998). However, considering the wave set-up as an effect on the internal water level and not a general higher inflow than outflow, as assumed by Barends \& van Hoven (2007), the observed spatial layout is rather more likely. The difference to the results of Losada et al. (1998) can be caused by the different core materials (sand instead of gravel).

Second, the analysis is performed by considering all tests with regular waves and the results are plotted in Figure 10, showing a good correlation between relative internal wave set-up $\eta_{\max , \text { int }} / \mathrm{L}_{0}$ and surf similarity parameter $\xi_{\mathrm{m}}$. Like for the external wave set-up (see Figure 7 and eq. 5 for regular waves) a prediction formula is also developed for the internal set-up (see Figure 10 and eq. 7).

$$
\text { regular waves: } \frac{\eta_{\max , \text { int }}}{L_{0}}=0.02 \cdot \xi_{m}^{-1.5}
$$

Generally, the internal wave set-up is smaller than the external, but the difference strongly decreases with increasing surf similarity parameter and it becomes negligibly small for $\xi_{\mathrm{m}}>4$.

Because the differences between the different breaker types in Figure 9 could also be caused by the test duration of each test (test duration $=100 \cdot \mathrm{T}$ ) leading to differently developed pore pressures (cf. Figure $8 \mathrm{~b}$ ), a further analysis was performed by considering the development of the internal set-up in time as shown exemplarily for the plunging breaker case in Figure 11.

In time steps of about $78 \mathrm{~s}$ (except for the first one), the internal mean water level is given. After $70 \mathrm{~s}$ an almost linear increase of the internal set-up can be observed which only differs slightly for the time step from $226 \mathrm{~s}$ to $305 \mathrm{~s}$. Afterwards, the increase is slower but it continues until the last time step $(540 \mathrm{~s})$. The set-up on the slope (maximum of EMWL) is, however, reached after about $100 \mathrm{~s}$. In consequence, it can be assumed, that the development of the internal set-up is not completed by the end of test. Therefore, a different result is expected for the IMWL in tests with irregular waves which were performed with about 1000 waves whereas only 100 waves per tests were used for the regular wave tests. 


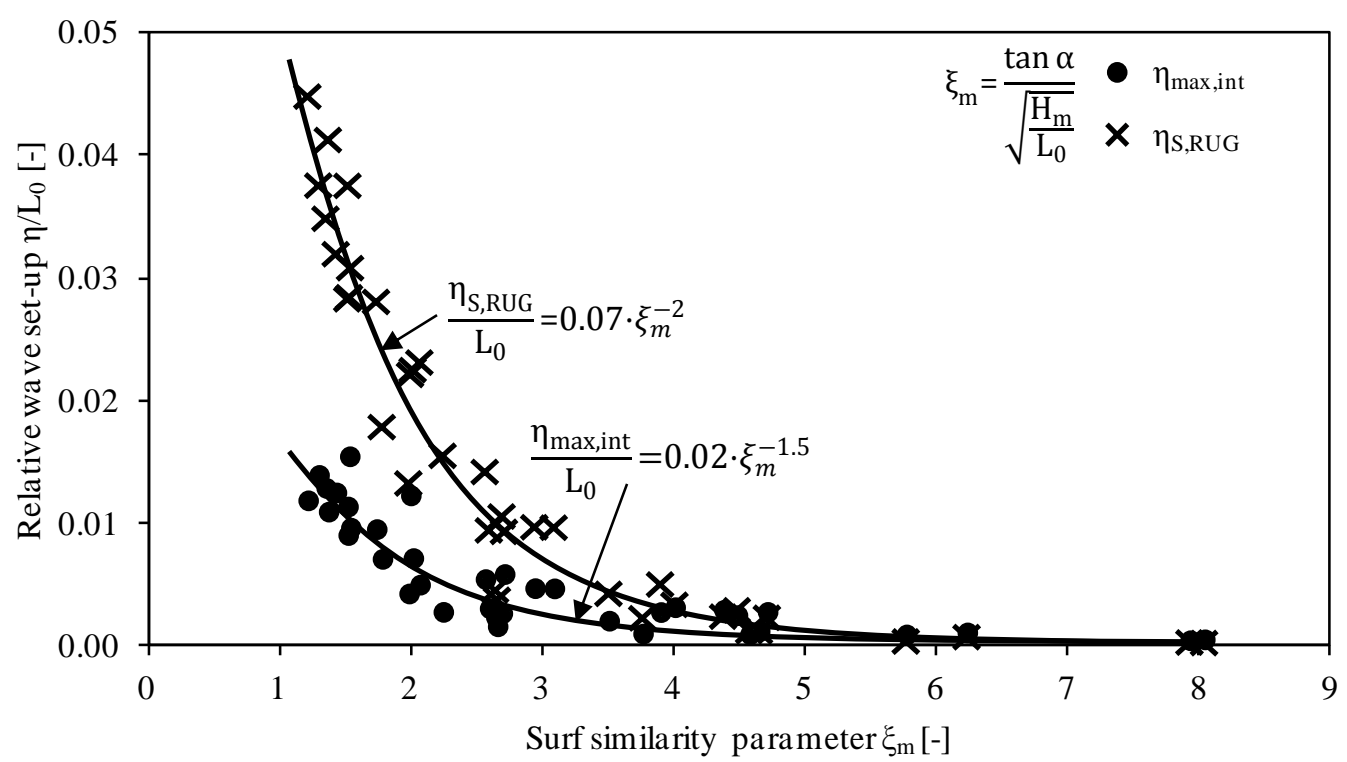

Figure 10. Internal and external wave set-up for regular waves.

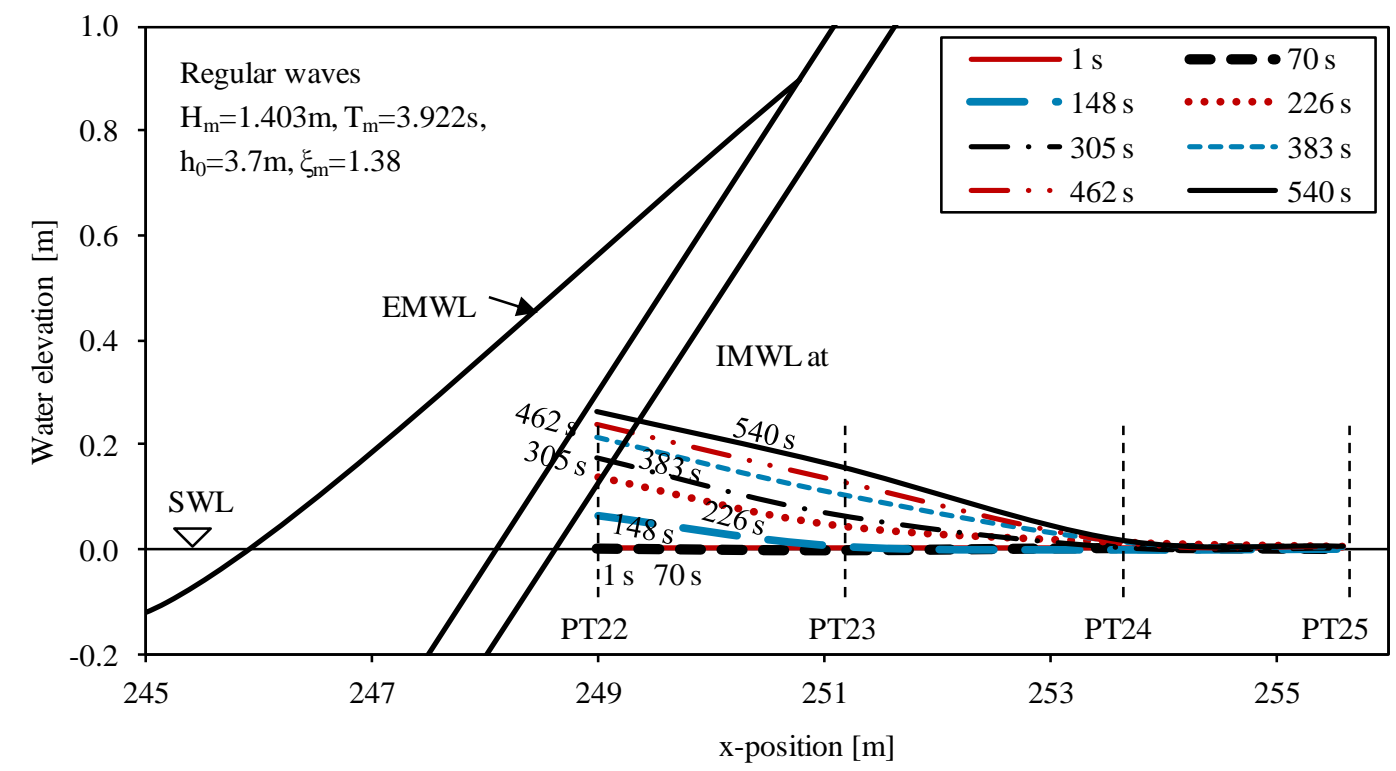

Figure 11. Example of the temporal development of the IMWL exemplarily for regular waves and plunging breakers (EMWL over entire test duration and IMWL for the indicated point in time).

\section{Irregular wave tests}

Based on the procedure used for the regular wave tests (Figure 8), the internal set-up for the irregular wave tests is determined as shown in Figure 12. The internal set-up is determined for the time frame starting from the end of the development of the internal set-up up to the end of the wave generation. 
a) Wave run-up and set-up at RUG1+2

$\mathrm{H}_{\mathrm{m} 0}=0.948 \mathrm{~m}, \mathrm{~T}_{\mathrm{m}-1,0}=4.626 \mathrm{~s}, \mathrm{~h}_{0}=3.9 \mathrm{~m}, \xi_{\mathrm{m}-1,0}=1.98$

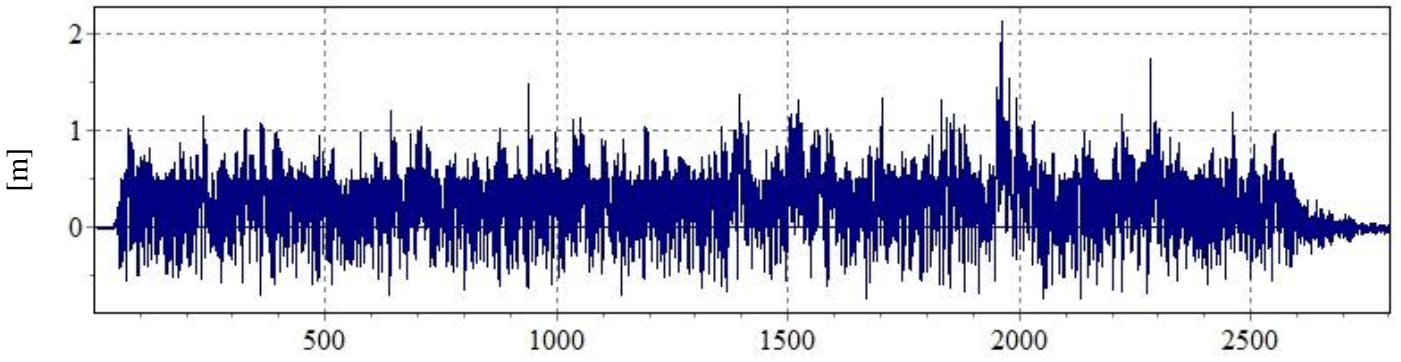

b) Pore pressure at PT22

Time $[\mathrm{s}]$

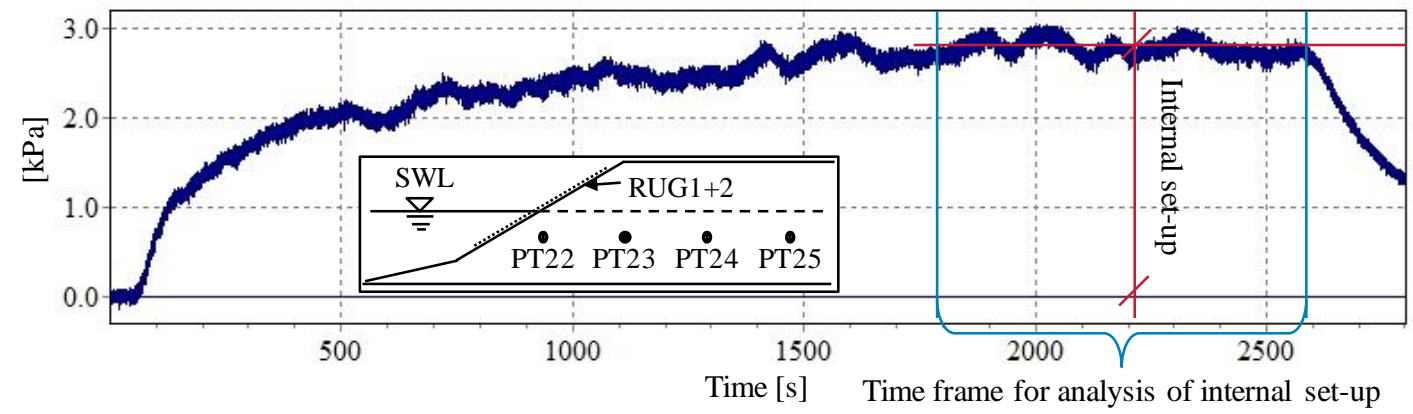

Figure 12. Determination of internal set-up in the sand foundation for irregular wave tests.

The same analysis as presented for regular waves in Figure 9 is also performed for the tests with irregular waves (Figure 13). Four representative tests with different breaker types are selected and their respective EMWL and IMWL are plotted together. The results of the tests with irregular waves differ greatly from those of the tests with regular waves. For all breaker types a larger internal set-up than external wave set-up is found. The smallest difference between wave set-up on the slope and at PT22 (nearest to the slope surface) is observed for the plunging breaker type followed by the plungingcollapsing breaker. The largest difference is found for the collapsing breaker and for the surging breaker an evaluation is again difficult due to the very small values for the IMWL and EMWL.

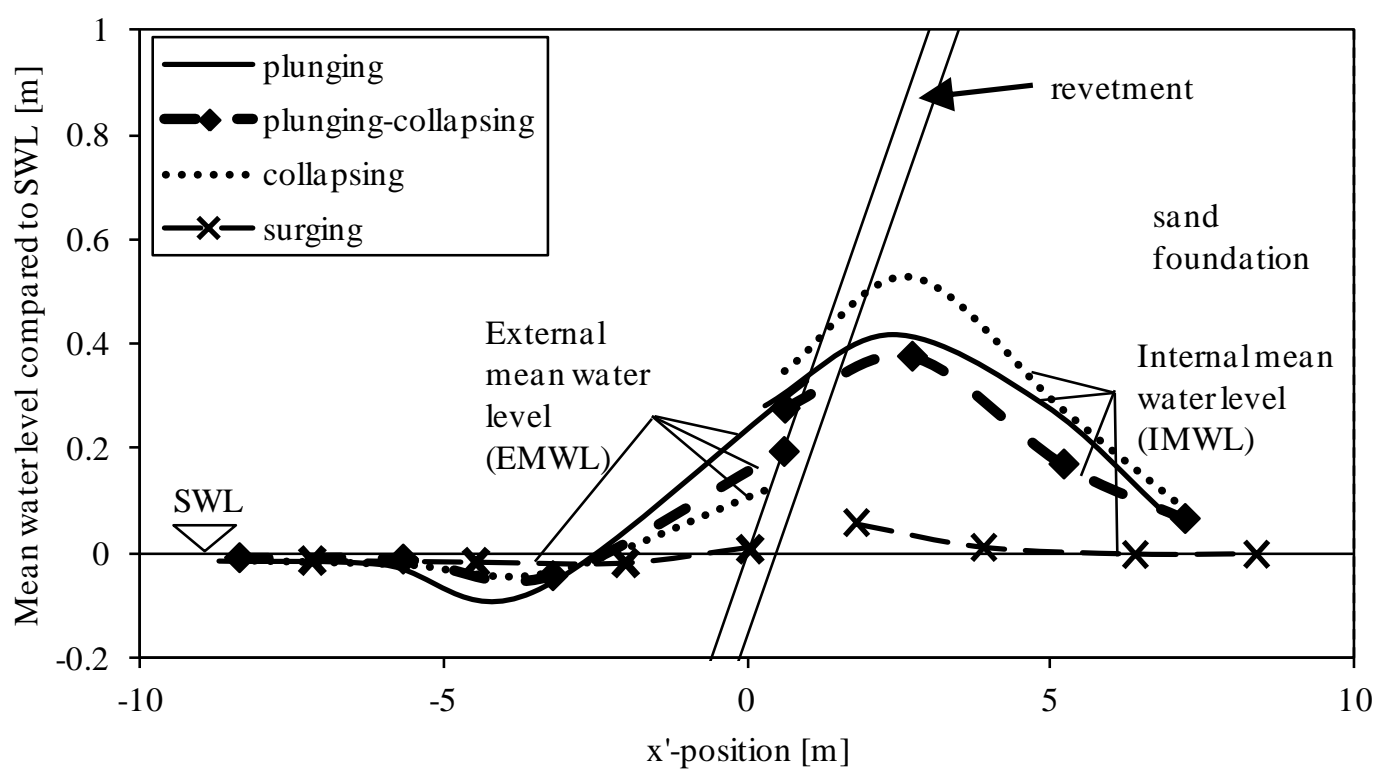

Figure 13. External and internal mean water level for representative tests with irregular waves and different breaker types. 
Apart from all the differences between the tests with regular and irregular waves for the IMWL, one finding from the regular wave tests can be confirmed by the tests with irregular waves: the location of the maximum internal wave set-up is still near the revetment.

Another feature of the IMWL for tests with irregular waves is the position of the maximum elevation which is further inside the revetment than for the regular waves. This maximum internal wave set-up $\eta_{\text {max,int }}$ is plotted as a relative parameter $\eta_{\text {max,int }} / L_{0}$ versus the surf similarity parameter $\xi_{\mathrm{m}-1,0}$ in Figure 14. The results indicate a higher maximum internal wave set-up than wave set-up on the slope surface for all surf similarity parameters. This is also shown by the prediction formulae given for the internal wave set-up and the internal wave set-up. Both formulae (eqs. 6 and 8 ) only differ in the power component of the surf similarity parameter ( -1.5 for internal wave set-up instead of -2.0 for external wave set-up).

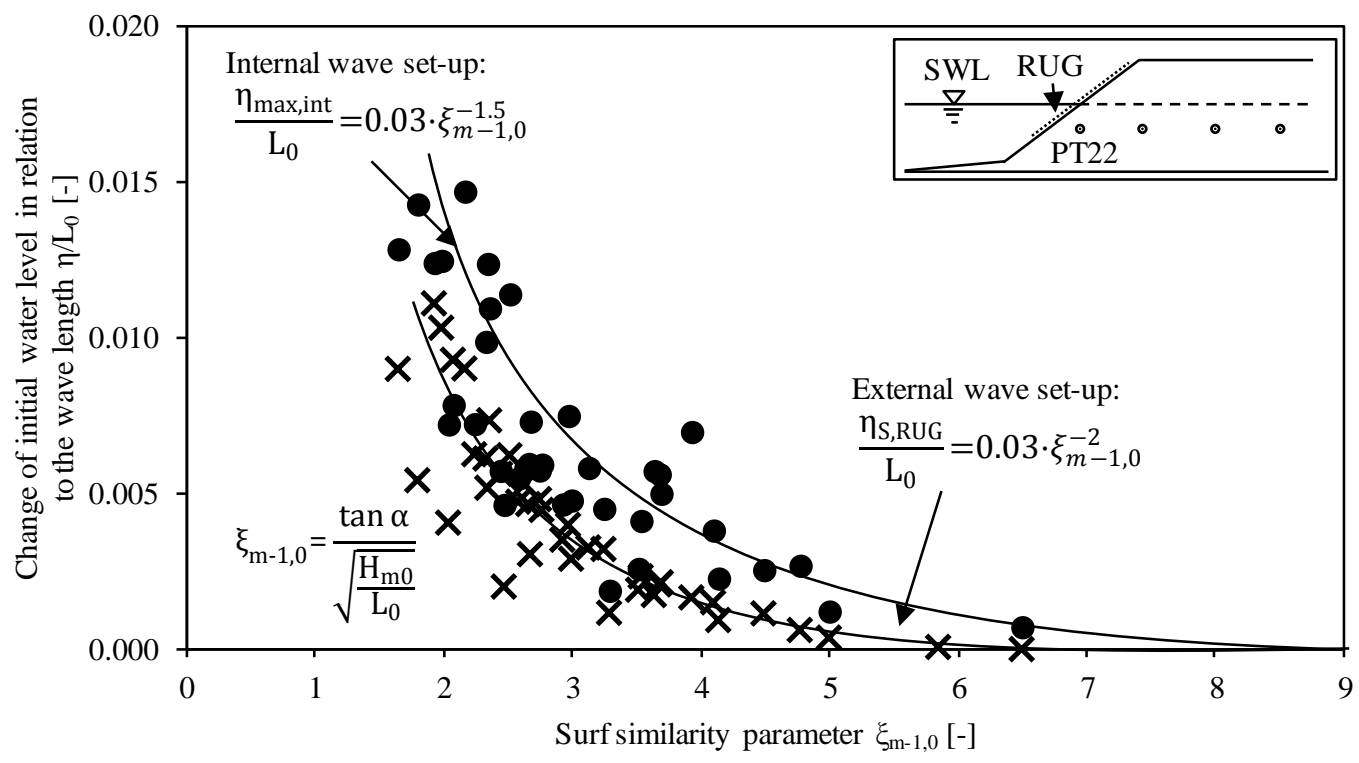

Figure 14. Internal and external wave set-up for irregular waves.

$$
\text { irregular waves: } \frac{\eta_{\max , i n t}}{L_{0}}=0.03 \cdot \xi_{m-1,0}^{-1.5}
$$

Generally, a good correlation between the maximum internal set-up $\eta_{\max , \text { int }} / \mathrm{L}_{0}$ and the surf similarity parameter $\xi_{\mathrm{m}}\left(\xi_{\mathrm{m}-1,0}\right)$ is found. The internal set-up for regular waves is found to be incomplete at the end of the test duration. The effect of the external wave set-up on the slope on the internal set-up depends on the breaker type for regular and irregular wave tests.

\section{SPATIAL LAYOUT OF THE MEAN WATER LEVEL}

To get an overview of the generalised spatial layout of the mean water level, in comparison to the representative tests, a dimensionless plot is provided in Figure 15 for all results from tests with irregular waves. The relative wave set-up $\eta_{\mathrm{S}, \mathrm{RUG}} / \mathrm{L}_{0}$ is shown against the relative distance from $\mathrm{SWL}$ $\mathrm{x}^{\prime} / \mathrm{H}_{\mathrm{m} 0} . \mathrm{x}^{\prime}$ is here the horizontal distance from the shoreline where seaward positions are considered negative (see also Figure 9 and Figure 13). Even though a large amount of scatter is present in the figure, a clear trend is visible in the data points. From the revetment into the sand foundation, the relative set-up is increasing up to $\eta_{\mathrm{S}, \mathrm{RUG}} / \mathrm{L}_{0}=0.015$ for $\mathrm{x}^{\prime} / \mathrm{H}_{\mathrm{m} 0} \approx 4$. For further increasing relative distances, the relative set-up is decreasing slowly.

Although the tendency is similar for all tests, a general approach based on this data is not advisable due to the high scatter. However, a further separation according to for example the surf similarity parameter might enable a prediction approach. This is, therefore, considered for further research. 


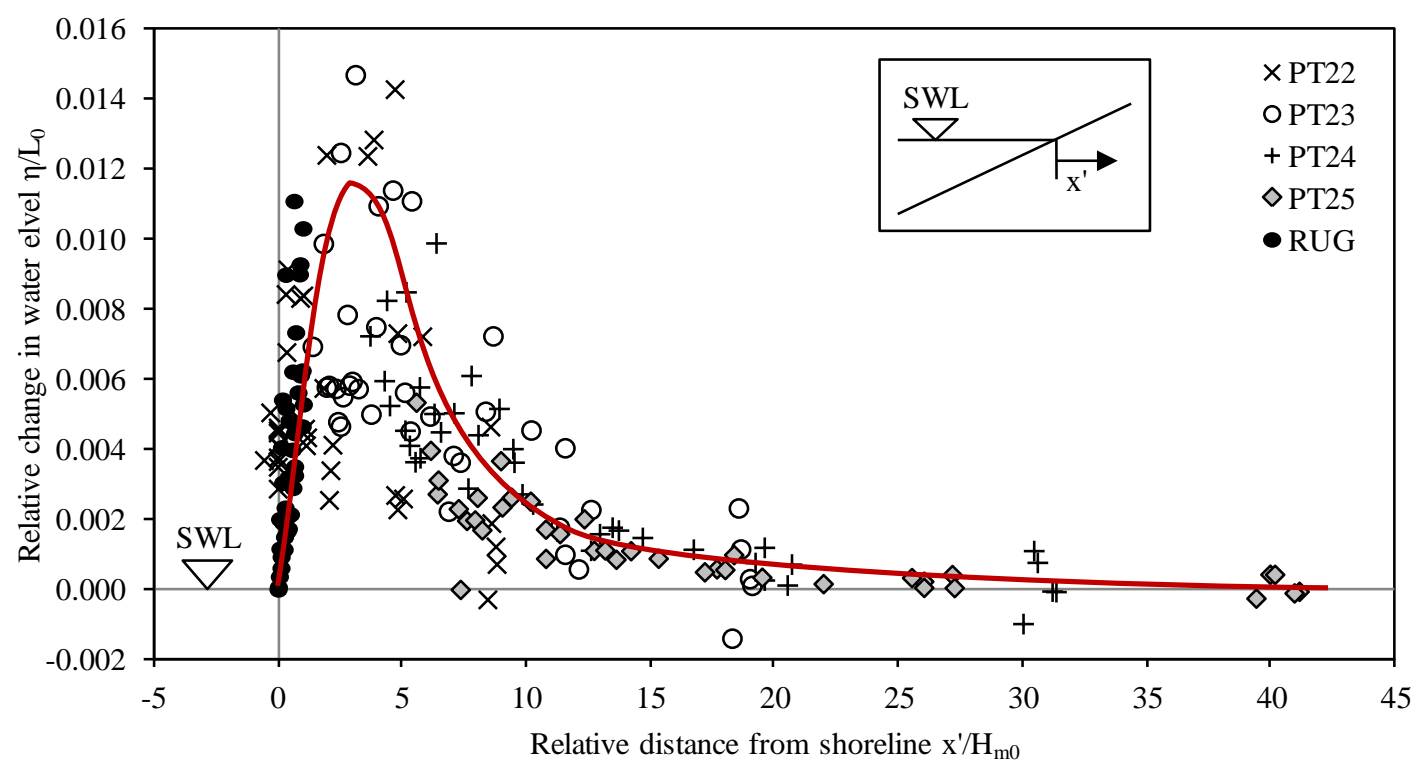

Figure 15. Wave set-up on the slope and EMWL over a dimensionless distance for tests with irregular waves.

\section{SUMMARY OF KEY RESULTS}

The key results of the analyses of the relation between relative wave set-up and surf similarity parameters by defining the relative set-up as $\eta_{S} / L_{0}$ instead of the commonly used $\eta_{S} / H_{m}$ are summarised in Figure 16 with prediction formulae for both external and internal set-up induced by regular and irregular waves. Moreover, the uncertainty associated with these prediction formulae are also described by the coefficient of variation $\sigma$ ' which is determined by using eq. 9 :

$$
\sigma^{\prime}=\sqrt{\frac{1}{(\mathrm{n}-1)} \cdot \sum_{\mathrm{i}=1}^{\mathrm{n}}\left(\frac{\mathrm{y}_{\mathrm{m}}}{\mathrm{f}\left(\mathrm{x}_{\mathrm{mi}}\right)}-1\right)^{2}}
$$

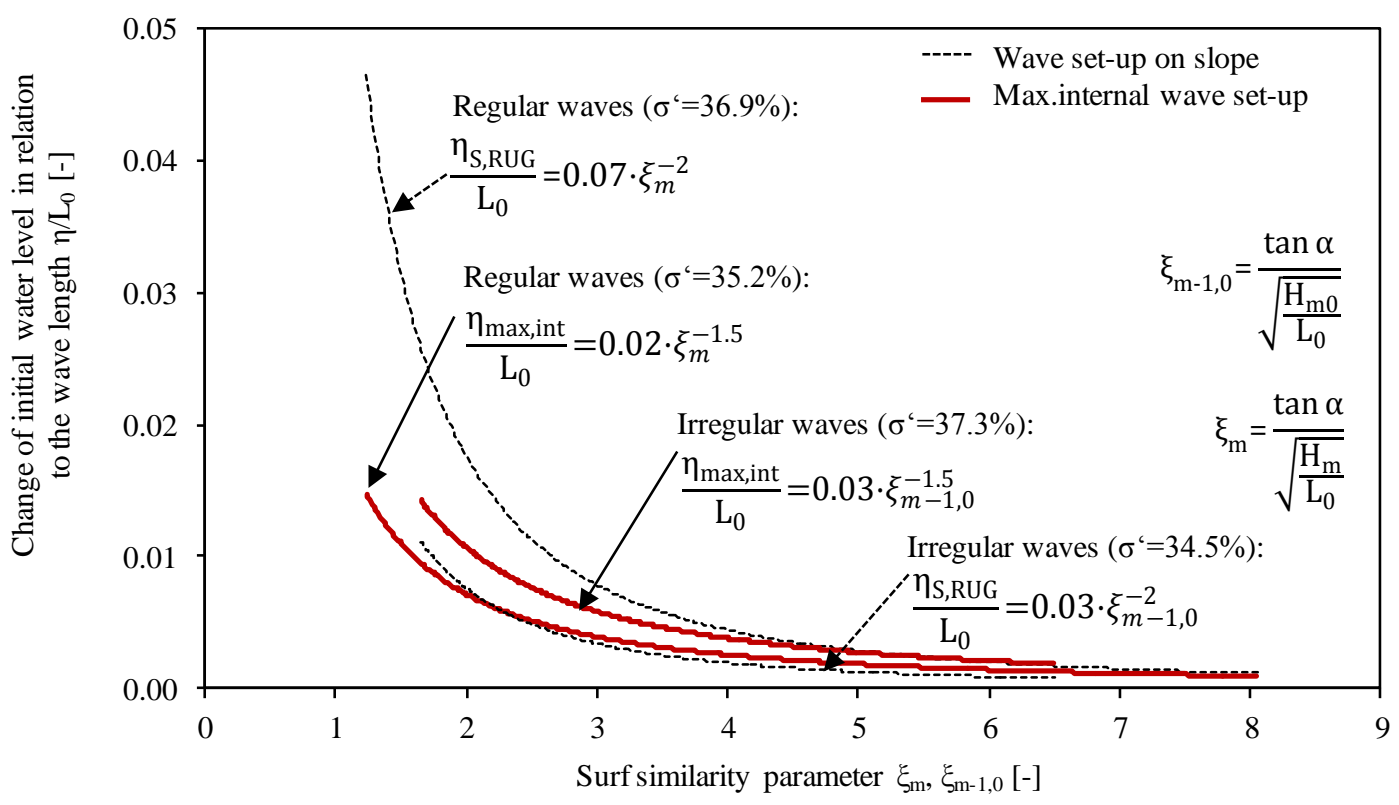

Figure 16. Internal and external wave set-up for regular and irregular waves. 


\section{CONCLUDING REMARKS AND OUTLOOK}

The analysis of the results from the large-scale tests performed in GWK with a porous revetment slope 1:3 have shown that the commonly proposed linear relationship between relative wave set-up $\eta_{\mathrm{S}} / \mathrm{H}$ and surf similarity parameter $\xi$ is not appropriate to describe the external wave set-up on a porous revetment slope and the related internal wave set-up in the sand foundation beneath the revetment. For both, non-linear relationships of the relative wave set-up $\eta_{\mathrm{S}} / \mathrm{L}_{0}$ as a function of surf similarity parameter $\xi$ were found to be more appropriate. Accordingly, prediction formulae were derived for the external and internal set-up induced by regular waves as well as by irregular waves (see summary in Figure 16).

Moreover, the results have also shown that a variation of the slope steepness will be required in further studies. Consideration of different revetment porosities might also help to identify the effect of the roughness and the porosity separately. Especially, a test series with a smooth impermeable slope as a reference case would be very helpful. Further tests with a higher spatial resolution to measure the wave set down in front of the revetment slope will be needed.

A more systematic parameter study using the RANS-VOF model COBRAS-UC (description in e.g. Losada et al. 2008) validated by the existing data has just been performed by varying among others the slope steepness tan $\alpha$ and the thicknesses $d_{\text {rev }}$ of the bonded porous revetment. The results of these further analyses will be published in a forthcoming paper.

Furthermore, experiments with revetments of different porosities and roughness are also planned in the frame of another PhD research project at the Leichtweiß-Institute (LWI), so that the effect of these parameters together with that of the slope steepness on the external and internal wave set up can also be determined and compared to the results of the numerical simulations.

\section{ACKNOWLEDGMENTS}

The $\mathrm{PhD}$ research project "Process analysis and model development for wave loading of porous bonded revetments" is funded by Deutsche Bundesstiftung Umwelt (dbu). The large-scale experiments in GWK were financed by BASF Polyurethanes GmbH and conducted with the support of Mr. T. Staal, Dr. S. Schimmels and Mr. M. Kudella. The support of all parties is greatly appreciated.

\section{REFERENCES}

Barends, F.; van Hoven, A. 2007. Internal setup in porous dams and dikes, Proceedings of the 14th European Conference on Soil Mechanics and Geotechnical Engineering, pp. pp. 821-826.

Hanslow, D.; Nielsen, P. 1993. Shoreline Set-Up on Natural Beaches, Journal of Coastal Research, pp. $1-10$.

Longuet-Higgins, M. S.; Stewart, R. w. 1964. Radiation stresses in water waves; a physical discussion, with applications, Deep Sea Research and Oceanographic Abstracts, 11, pp. pp. 529-562.

Losada, I. J.; Dalrymple, R. A.; Losada, M. A. 1998. Wave-induced mean flows in vertical rubble mound structures, Coastal Engineering, 35, pp. 251-281.

Losada, I. J.; Lara, J. L.; Guanche, R.; Gonzalez-Ondina, J. M. 2008. Numerical analysis of wave overtopping of rubble mound breakwaters, Coastal Engineering, 55, pp. 47-62.

Ludwigs, G.; Oumeraci, H. 2011. Dynamic response of PBA revetments and subsoil to wave loads, Coastal Structures, Yokohama, Japan (In print).

Ludwigs, G.; Oumeraci, H.; Staal, T. 2010. Wave loads on and beneath bonded permeable revetments (Poster), 32nd International Conference on Coastal Engineering, Shanghai, China.

Oumeraci, H.; Staal, T.; Pfoertner, S.; Kudella, M.; Schimmels, S.; Verhagen, H. 2010a. Hydraulic performance of elastomeric bonded permeable revetments and subsoil response to wave loads, 32nd International Conference on Coastal Engineering, Shanghai, China.

Oumeraci, H.; Staal, T.; Pfoertner, S.; Ludwigs, G.; Kudella, M. 2010b. Hydraulic performance, wave loading and response of Elastocoast revetments and their foundation - A large scale model study -. Braunschweig, Germany (Berichte Leichtweiß-Institut für Wasserbau, Technische Universität Braunschweig).

Oumeraci, H.; Staal, T.; Pförtner, S.; Ludwigs, G. 2012. Hydraulic performance, wave loading and response of PBA revetments and their foundations, European Journal of Environmental and Civil Engineering - Special Issue.

Stockdon, H. F.; Holman, R. A.; Howd, P. A.; Sallenger, A. H., JR. 2006. Empirical parameterization of setup, swash, and runup, Coastal Engineering, 53, pp. 573-588. 